RESEARCH REPORT

\title{
Neighbourhood mortality inequalities in New York City, 1989-1991 and 1999-2001
}

\author{
Adam M Karpati, Mary T Bassett, Colin McCord
}

J Epidemiol Community Health 2006;60:1060-1064. doi: 10.1136/jech.2006.047100

See end of article for authors' affiliations .....................

Correspondence to: A Karpati, New York City Department of Health and Mental Hygiene, Brooklyn District Public Health Office, 485 Throop Avenue, Brooklyn, NY 11221, USA: akarpati@health.nyc.gov

Accepted 12 May 2006

\begin{abstract}
Objectives: To examine whether inequalities in mortality across socioeconomically diverse neighbourhoods changed alongside the decline in mortality observed in New York City between 1990 and 2000. Design: Cross-sectional analysis of neighbourhood-level vital statistics. Setting: New York City, 1989-1991 and 1999-2001.

Main results: In both poor and wealthy neighbourhoods, age-adjusted mortality for most causes declined between the time periods, although mortality from diabetes increased. Relative inequalities decreased slightly-largely in the under 65 years population-although all-cause rates in 1999-2001 were still 50\% higher, and rates of years of potential life lost before age 65 years were 150\% higher, in the poorest communities than in the wealthiest ones (relative index of inequality 1.7 and 3.3, respectively). The relative index of inequality for mortality from AIDS increased from 4.7 to 13.9 . Over $50 \%$ of the excess mortality in the poorest neighbourhoods in 1999-2001 was due to cardiovascular disease, AIDS and cancer. Conclusions: In New York City, despite substantial declines in absolute mortality and rate differences between poor and wealthy neighbourhoods, great relative socioeconomic inequalities in mortality persist.
\end{abstract}

E liminating health inequalities between populations of different social and economic conditions is a central mission of public health. Such health inequalities are dramatic in US cities, in which substantial and persistent health disparities often exist between neighbourhoods in the same urban area. ${ }^{1-3}$ Measuring and monitoring these health disparities over time are crucial steps towards the goal of their elimination. Cities need to routinely collect neighbourhood-level data to identify priority preventable conditions and to track inequalities among their typically diverse populaces. Having such data enables local governments to target not only citywide average levels of health but also differences in health status between communities, thereby explicitly incorporating an inequality perspective into planning and policy making. ${ }^{4}$ Local public health agencies' routine examination of health inequalities can also improve our understanding of how poverty, discrimination, other social disadvantage and contextual effects of neighbourhoods affect health in urban settings.

Recent evidence from the UK indicates that socioeconomic inequalities in mortality have widened over the past two decades, despite absolute improvements in life expectancy in communities at all levels of poverty (as measured by area deprivation). ${ }^{5}$ Other analyses that use area indicators of socioeconomic status have found mixed improvements and declines in urban health disparities. ${ }^{67}$ In New York City, between 1990 and 2000, mortality declined at a faster rate than in the previous four decades. ${ }^{8}$ We examined this change in mortality at the neighbourhood level to determine whether there were concomitant changes in mortality inequalities.

\section{METHODS}

\section{Mortality data}

We obtained mortality data from the Office of Vital Statistics, New York City Department of Health and Mental Hygiene for 1999-2001 and 1989-91. Cause of death was defined as the underlying cause coded from death certificates using the International Classifications of Disease (ICD) revision 10 (for 1999-2001) and revision 9 (for the years 1989-1991). We compiled the numbers of all-cause deaths and cause-specific deaths for the 12 leading causes of death among New York City residents who died in New York City from 1999 to 2001 (each contributed at least $1 \%$ of all deaths; infant deaths were excluded). These causes, with their corresponding ICD9 and ICD-10 codes and comparability ratios, ${ }^{1}$ are: cardiovascular diseases including heart disease and stroke (390434, 436-448; I00-I78; 0.99), malignancies (140-208; C00C97; 1.01), pneumonia and influenza (480-487; J10-J18; $0.70)$, AIDS (042-044; B20-B24; 1.06), diabetes (250; E10E14; 1.01), chronic lower respiratory diseases (490-494, 496; J40-J47; 1.05), external causes (eg, accidents, injuries and poisonings; E800-E869, E880-E929; V01-X59, Y85-Y86; 1.03), renal disease (580-589; N00-N07, N17-N19, N25-N27; 1.23), drug-related $(304,850.0,854.1,855.2,858.8 ;$ F11-F16, F18-F19, X40-X42, X44; n/a), homicide (E960-E969; X85-Y09, Y87.1; 1.00), septicaemia (disseminated infections; 038; A40-A41; 1.19) and liver disease (571; K70, K73-K74; 1.04). ${ }^{9}$

\section{Socioeconomic status data and neighbourhood definition}

We chose the percentage of population living under the federal poverty line as a measure of socioeconomic status (SES). The federal poverty line is a threshold determined for a given family according to its annual income, size and age composition, and is set according to a formula developed in 1963-4, indexed for inflation (the formula uses an estimate for a family's food budget and a multiplier for all other household needs). ${ }^{10}$ This metric is commonly used in US disparities research and performs comparably to other

Abbreviations: ICD, International Classifications of Disease; RII, relative index of inequality; SES, socioeconomic status; YPLL, years of potential life lost before age 65

iThe comparability ratio indicates the correspondence between the ICD9 and ICD-10 coding systems, based on double coding of a reference set of death certificates, and is calculated as,

$C_{i}=D_{i}, I C D-10 / D_{i}, I C D-9$

where $D_{i}$ is the cause-specific number of deaths. 
Table 1 Mortality and mortality inequalities, New York City neighbourhoods, 1989-91 and 1999-2001*

\begin{tabular}{|c|c|c|c|c|c|c|c|c|}
\hline \multirow[b]{2}{*}{ Causet } & \multicolumn{2}{|c|}{$\begin{array}{l}\text { Rate in poorest } \\
\text { neighbourhoods }\end{array}$} & \multicolumn{2}{|c|}{$\begin{array}{l}\text { Rate in wealthiest } \\
\text { neighbourhoods }\end{array}$} & \multicolumn{2}{|c|}{ Ratio poor: wealthył } & \multicolumn{2}{|l|}{ RIl‡ } \\
\hline & 1989-1991 & 1999-2001 & 1989-1991 & 1999-2001 & 1989-1991 & 1999-2001 & 1989-1991 & 1999-2001 \\
\hline All & 1248 & 975 & 771 & 637 & 1.6 & 1.5 & $1.9 \S$ & $1.7 \S$ \\
\hline YPLL-65 & 12814 & 6059 & 4284 & 2429 & $3.0 \S$ & $2.5 \S$ & $4.2 \S$ & $3.3 \S$ \\
\hline Heart disease & 471 & 391 & 380 & 312 & 1.2 & 1.3 & 1.4 & 1.3 \\
\hline Malignancies & 219 & 206 & 177 & 159 & 1.2 & 1.3 & 1.3 & 1.4 \\
\hline AIDS & 98 & 60 & 26 & 10 & $3.7 \S$ & $6.1 \S$ & $4.7 \S$ & $13.9 \S$ \\
\hline Diabetes & 24 & 46 & 9 & 14 & 2.8 & 3.3 & 4.0 & 4.6 \\
\hline Influenza and pneumonia & 60 & 42 & 34 & 29 & 1.8 & 1.5 & $2.1 \S$ & $1.6 \S$ \\
\hline Chronic lung disease & 28 & 28 & 18 & 19 & 1.5 & 1.5 & 1.7 & 1.6 \\
\hline Drug-related & 22 & 21 & 4 & 6 & 5.6 & 3.5 & $11.0 \S$ & $5.7 \S$ \\
\hline External causes & 26 & 17 & 16 & 10 & 1.7 & 1.7 & 1.9 & 2.0 \\
\hline Liver disease & 24 & 16 & 8 & 4 & 3.0 & 3.6 & 4.4 & 5.4 \\
\hline Renal disease & 14 & 16 & 7 & 7 & 2.0 & 2.1 & 2.5 & 2.7 \\
\hline Homicide & 52 & 15 & 9 & 3 & 6.0 & 5.3 & 12.7 & 9.0 \\
\hline Septicaemia & 18 & 14 & 6 & 5 & 3.0 & 2.7 & 4.1 & 3.9 \\
\hline \multicolumn{9}{|c|}{$\begin{array}{l}\text { RII, relative index of inequality; YPLL, years of potential life lost before age } 65 \text {. } \\
\text { *All rates per } 100000 \text { population, rounded to nearest whole number. } \\
\text { † Causes are ranked by the } 1999-2001 \text { rate in the poorest neighbourhoods. } \\
\text { †All rate ratios and Rll are } p<0.05 \text {. } \\
\text { §Rate ratios and Rll whose } 95 \% \text { confidence intervals do not overlap. }\end{array}$} \\
\hline
\end{tabular}

measures of economic deprivation (eg, median household income) in detecting inequalities in mortality by area. ${ }^{11}$ We obtained the population and percentage of population living below the federal poverty line from the 1990 and 2000 US census (compiled by the New York City Department of City Planning). ${ }^{12}$ Neighbourhoods were defined by census tract aggregations known as "community districts", for which certain planning and oversight duties are performed by local representatives and which have been standard units of neighbourhood aggregation used by New York City municipal agencies since 1975. The population of New York City was 7.3 million in 1990 and 8 million in 2000. There are 59 community districts; the median population in 2000 was 128000 . The median number of census tracts within community districts in 2000 was 36 (range 15-105). Neighbourhoods were categorised into four groups in each decade, based on quartiles of increasing poverty (see fig 1). Larger groupings of geography and time increase the stability of estimates, especially when generating analyses of relatively rare outcomes in relatively small populations. ${ }^{13}$

\section{Analysis}

We calculated all-cause and cause-specific death rates, as well as rates of years of life lost before age 65 (YPLL-65) for each quartile of neighbourhoods for both time periods. All rates were age-standardised to the National Center for Health Statistics' year 2000 standard US population.

To measure and describe socioeconomic inequalities in mortality, we calculated mortality ratios between the poorest quarter of neighbourhoods and the wealthiest. We calculated 95\% confidence intervals (CI) for the rate ratios using the standardisation weights and a variance estimator that assumes that the death rate follows a Poisson distribution. $^{14}{ }^{15}$ We also calculated the "excess" mortality in the poorest quarter of neighbourhoods by multiplying causespecific and age-specific rates in the wealthiest areas by the populations of the poorest. Finally, we calculated the relative index of inequality (RII) for all outcomes. The RII is a measure that summarises the health inequality between populations that are ordered by a particular characteristic (by socioeconomic status). ${ }^{16}{ }^{17}$ In contrast with simple indices such as rate ratios, which compare two strata, the RII incorporates data from all strata (from all four quartiles of neighbourhood poverty). It is a model-based estimate that, in this analysis, can be interpreted as the rate ratio between the theoretically highest-income and lowest-income groups. It has an additional advantage in that it is sensitive not only to the stratum-specific mortality but also to the proportion of the population in each income stratum. We calculated the RII by fitting a Poisson regression model for the expected number of deaths in each poverty quartile as a function of their cumulative population distribution. ${ }^{14}$

\section{RESULTS}

The analysis included 206166 deaths in 1989-91 and 170630 deaths in 1999-2001.

All-cause mortality and YPLL-65 improved substantially in both poor and wealthy neighbourhoods (table 1). Cardiovascular disease and cancer were the leading causes of death in all neighbourhoods in both time periods. In poor neighbourhoods, all-cause and cause-specific mortalities

New York City community districts $(n=59)$

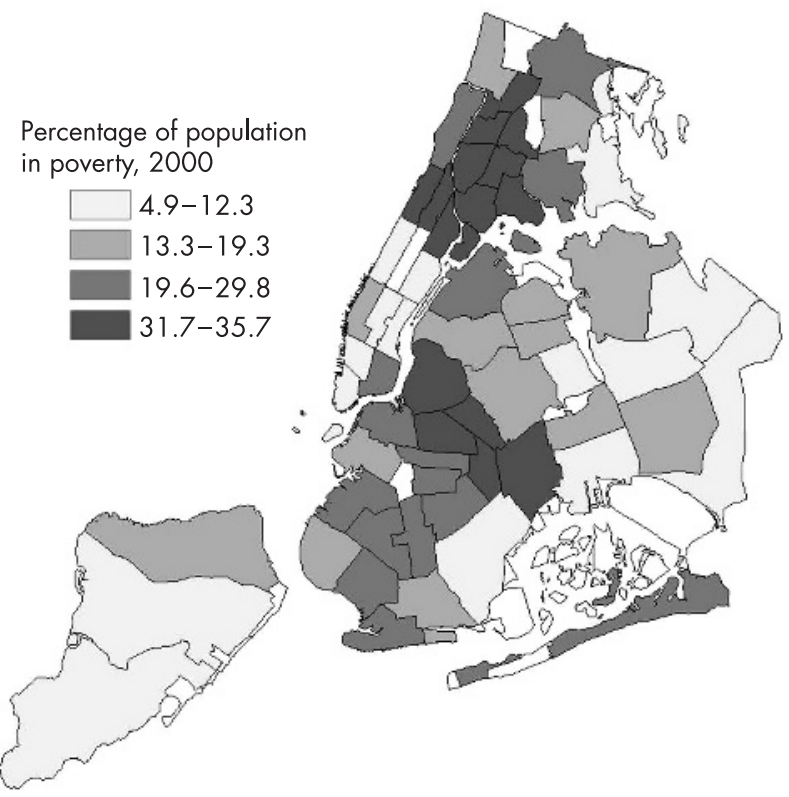

Figure 1 Distribution of population in poverty, New York City, 2000. 
Table 2 Causes of excess mortality in the 15 poorest neighbourhoods of New York City, 1999-2001

\begin{tabular}{|c|c|c|c|c|c|}
\hline Cause & $\begin{array}{l}\text { No of excess deaths } \\
1999-2001 \\
\text { (1-year average) }\end{array}$ & $\begin{array}{l}\% \text { of excess } \\
\text { deaths }\end{array}$ & Cumulative \% & $\begin{array}{l}\text { No of excess deaths } \\
1989-1991 \\
\text { (1-year average) }\end{array}$ & $\begin{array}{l}\text { Excess deaths averted } \\
\text { per year } \\
\text { (1989-91 v 1999-2001) }\end{array}$ \\
\hline Cardiovascular diseases & 1019 & 23 & 23 & 1226 & 207 \\
\hline HIV/AIDS & 730 & 16 & 39 & 1094 & 364 \\
\hline Cancer & 591 & 13 & 52 & 535 & -56 \\
\hline Diabetes & 368 & 8 & 60 & 186 & -182 \\
\hline Homicide & 213 & 5 & 65 & 784 & 571 \\
\hline Drug-related & 213 & 5 & 70 & 267 & 54 \\
\hline Liver disease & 150 & 3 & 73 & 210 & 60 \\
\hline Pneumonia and influenza & 149 & 3 & 76 & 328 & 179 \\
\hline All other causes & 1049 & 23 & 100 & 2114 & 1065 \\
\hline All causes & 4482 & 100 & & 6744 & 2262 \\
\hline
\end{tabular}

declined, by as much as $71 \%$ for deaths from homicide. The only notable exception the rates of diabetes mortality, which increased $91 \%$. Rates also improved in the wealthiest neighbourhoods, again with the notable exception of diabetes, which also increased.

In both time periods, inequalities between mortality in poor and wealthy neighbourhoods existed for all causes of death and for all-cause YPLL-65. In the more recent time period of 1999-2001, all-cause mortalities were 50\% higher in the poorest quarter of neighbourhoods and rates of YPLL-65 were 2.5 times higher. The RII, which incorporates data from all four neighbourhood groups, was 1.7 for all-cause mortality and 3.3 for YPLL-65. RIIs were consistently greater than rate ratios because the predicted rates at the ends ( 0 and 1) of the poverty-ordered population distribution were more extreme (lower and higher) than the predicted rates at the midpoints of the poorest and wealthiest strata. The highest RII in the 1999-2001 period were for AIDS (RII $=13.9,95 \%$ CI 11.5 to 16.7 ), homicide ( $\mathrm{RII}=9.0,95 \%$ CI 6.5 to 12.5 ), drug-related causes $(\mathrm{RII}=5.7,95 \% \mathrm{CI} 4.4$ to 7.4$)$, liver disease (RII $=5.4,95 \%$ CI 4.0 to 7.2 ) and diabetes (RII $=4.6$, $95 \%$ CI 3.9 to 5.4 ). The lowest RII were for cardiovascular disease and cancer.

Inequalities significantly narrowed between 1989-91 and 1999-2001 for all-cause deaths (RII decreased from 1.9 to 1.7), YPLL-65 (RII decreased from 4.2 to 3.3), influenza and pneumonia (RII decreased from 2.1 to 1.6 ) and drug-related causes (RII decreased from 11.0 to 5.7). Conversely, inequalities significantly increased for AIDS (RII increased from 4.7 to 13.9). Inequalities for the other conditions did not significantly change.

During 1999-2001, the leading cause of excess deaths in the poorest neighbourhoods was cardiovascular disease, contributing 1019 excess deaths or $23 \%$ of all excess deaths (table 2).

HIV/AIDS, cancers, diabetes, homicide and drug-related deaths each contributed approximately $\geqslant 5 \%$ of all excess deaths, and eight causes contributed around $75 \%$ of all excess deaths. In these leading causes, age-specific contributions to excess mortality also differed. For cardiovascular disease and cancer, for example, which together account for approximately two thirds of all deaths in New York City, the agespecific rate ratios were highest among younger age groups, declined among older age groups, and began to equalise or reverse for those aged $>85$ years (fig 2 ).

Total excess deaths declined between 1989-91 and 19992001, from an average of 6744 to 4482 excess deaths per year in poor neighbourhoods (table 2). A total of 2262, or one third, fewer excess deaths per year occurred in poor neighbourhoods as a result of mortality reductions over the decade.

\section{CONCLUSIONS}

Between 1989-91 and 1999-2001, mortality declined in both poor and wealthy neighbourhoods of New York City. Absolute inequalities in mortality, especially premature mortality, also declined over the decade. However, relative inequality improved only slightly, although there was greater

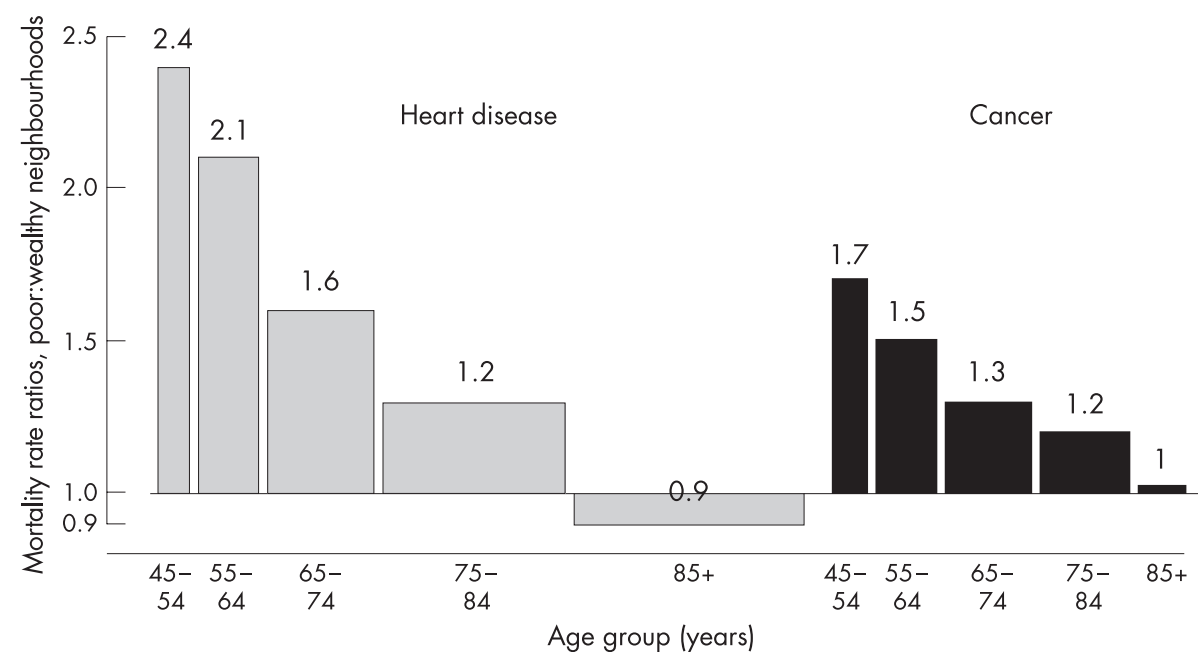

Figure 2 Age-specific mortality ratios between the poorest and wealthiest New York City neighbourhoods, 1999-2001. Width of bars proportional to age-specific numbers of deaths across both populations. 
improvement in YPLL-65. Cause-specific relative inequalities were generally unchanged, although there was a narrowing of the gap for drug-related causes and pneumonia or influenza. Inequality increased dramatically for mortality due to AIDS.

Changes in mortality from homicide show the distinction between absolute and relative inequalities as well as the persistence of inequalities despite substantial within-group improvements. Homicide mortality in poor neighbourhoods impressively declined by 37 per 100000 between 1989-91 and 1999-2001, whereas in wealthy neighbourhoods it declined by only 6 per 100000 . This resulted in the rate difference declining from 43 per 100000 to 12 per 100000 . However, the relative declines in each group were similar, producing mostly unchanged relative inequality.

AIDS mortality was the most unequal outcome along the socioeconomic gradient and became more unequal over the past decade, probably owing to a multifactorial combination of differential access to highly active antiretroviral treatment, timeliness of diagnosis and local infrastructure to deliver services, as well as less effective prevention efforts. ${ }^{18}$ Diabetes was the only major mortality indicator to worsen in New York City; moreover, disparities for this condition may have widened between poorer and wealthier neighbourhoods. The prevalence of obesity and diabetes show a similar SES gradient. ${ }^{19} 20$ Deaths from liver disease, largely owing to cirrhosis, were also highly and increasingly unequal. Conditions such as heart disease and cancer, although showing relatively low levels of inequality averaged across ages, were shown to be highly disparate in age-specific analyses. Moreover, despite relatively small age-adjusted rate ratios, the large number of deaths owing to heart disease and cancer resulted in these causes being ranked first and third in proportional contribution to excess mortality in the poorest neighbourhoods.

Greater SES-associated disparities exist when YPLL-65 are compared with the number of deaths at all ages. This finding reflects the degree to which AIDS, homicide and infant mortality, in which young ages at death contribute greatly to YPLL-65, are associated with poverty, as well as the fact that among other leading causes of premature death, such as heart disease and cancer, years of life lost per death are greater in poor neighbourhoods. This finding of continuing inequalities in mortality at younger ages is somewhat tempered, however, by the concomitant observation that this inequality has narrowed over the past decade.

Vital statistics data, which are abstracted from death certificates, do not include individual-level information on income. This analysis used an ecological measure from the US census, percentage in poverty, to describe the socioeconomic environment in which neighbourhood residents lived. Mortality differences between neighbourhoods with higher and lower poverty rates probably result from a complex combination of influences, including both compositional effects (eg, residents' incomes and race/ethnicities) and contextual effects (eg, neighbourhood deprivation or wealth, built environment characteristics and income inequality). ${ }^{21}$ The lack of robust SES data on death certificates and other public health data sources limits epidemiologists' ability to carry out effective SES-based disparities surveillance, which would ideally incorporate both individual-level and contextual-level measures of material deprivation. ${ }^{4}$ This would allow more nuanced distinctions between the health of those who live in poor neighbourhoods and the health of poor people.

Demographic shifts within neighbourhoods produce a limitation to interpreting temporal differences in mortality at the neighbourhood level. High mortality at the first time period may have reflected out-migration of healthier residents in preceding years; subsequent reductions in mortality might reflect in-migration of healthier populations. This analysis, therefore, focused more on comparing mortality inequalities between wealthier and poorer neighbourhoods in the two time periods, rather than on comparing the mortality within neighbourhoods or neighbourhood groups over time.

Findings from the earlier time period, 1989-91, may be influenced by particularities of the 1990 US census data collection in New York City. It is estimated that, citywide, there was an approximately $3 \%$ undercount in population in 1990 (corresponding to about 200000 people)..$^{22}$ The 2000 census undercount is estimated to have been $<1 \% .^{23}$ Residents of poor neighbourhoods and African American residents were most likely not to be counted in 1990. This phenomenon would produce artificially higher mortality for these populations in that time period, but would not be of a magnitude sufficient to change the overall findings and trends; US census estimates of the undercount ranged from $0.7 \%$ to $7.0 \%$ across the 59 neighbourhoods; the poorest and wealthiest quarter of neighbourhoods had estimated undercounts of $5.3 \%$ and $1.7 \%$, respectively (data not shown). ${ }^{22}$

This analysis used an area definition particular to New York City - the community district—because these areas have meaning and relevance to city residents, community organisations and government agencies despite their relatively large areas and populations. Census information is available for smaller geographical entities, such as census tracts, which would show demographic and socioeconomic heterogeneity within districts. However, within-district heterogeneity of poverty is limited: $80 \%$ of the population of the poorest quarter of community districts lives in the poorest quarter of census tracts; an additional $16 \%$ live in the next-poorest quarter of tracts. Similarly, $66 \%$ of the population of the wealthiest quarter of districts lives in the wealthiest quarter of tracts; an additional 26\% live in the next wealthiest. Any misclassification of the neighbourhoods' relative SES likely would probably attenuate the mortality inequalities found in this analysis; as such, these findings are likely to be conservative estimates.

Differential recording of the underlying cause of death in hospitals serving poorer versus wealthier populations might account for some cause-specific mortality differences, if deaths from one category were "shifted" into another. For example, this phenomenon may occur for deaths due to diabetes and cardiac disease. More detailed analysis, comparing medical history information with the underlying causeof-death designation on death certificates and subsequent coding into ICD categories, would provide useful insights. In addition, the ranking of leading causes of death is somewhat arbitrary. More or less inclusive groupings of causes obviously lead to higher or lower ranks-for example, designating all cancer deaths as "malignancies", rather than examining breast, lung and colon cancer deaths separately, or splitting "cardiovascular disease" into heart, stroke and hypertensive causes. Rankings per se, then, have limited meaning, but do provide some indication of absolute disease burden. Similarly, coding differences between revisions of the ICD are limitations to temporal comparisons of cause-specific rates.

Mortality differences between wealthier and poorer communities in New York City have been described previously. ${ }^{24-}$

${ }^{26}$ This analysis provides an update to these observations with recent data and sets benchmarks for research, policy and programmatic initiatives to reduce and eliminate health disparities. Public health benchmarking and surveillance should explicitly include measures of inequality, to complement monitoring of absolute rates of illness and death. Further research using area-based socioeconomic measures should focus on accounting for demographic change within 


\section{What is known on this topic}

- Socioeconomic inequalities in mortality exist in North America and Europe.

- Recent evidence suggests that the inequalities in the UK have widened in recent decades.

- Comparable data from the US, particularly in urban populations, are lacking.

\section{What this study adds}

- This study provides a comparison of mortality inequalities across New York City's neighbourhoods between 1990 and 2000, both for all causes and for specific causes.

- Mortality from almost all causes declined in both poor and wealthy neighbourhoods, but substantial inequalities remained.

\section{Policy implications}

- The findings of this analysis imply that strategies for successfully improving the absolute levels of health in populations may not necessarily also fully deal with health inequalities and that other approaches, targeting the root causes of health inequalities, are needed.

neighbourhoods to better understand secular changes in community health.

This analysis shows that considerable improvements have occurred in the past decade in the health of residents of poor neighbourhoods in New York City, but unacceptable inequalities persist. Differing, complementary strategies are probably necessary for further gains in particular outcomes and also for dealing with the shared determinants of persistent disparities across outcomes. AIDS, for example, is a condition in which great progress has occurred in both poor and wealthy communities. Specific programmes and policies to expand testing, assure linkage to life-saving treatment, provide ancillary mental health and substance use services, and promote medication adherence are all necessary to assure continued improvements. However, the persistent, dramatic inequality in mortality suggests that such targeted strategies need to be complemented by attention to the underlying exacerbators of the epidemic, such as poverty, lack of education, limited affordable housing and unemployment. Diabetes provides another example: dealing with this epidemic will require new and improved medical treatments and methods for promoting people to change their patterns of diet and physical activity. However, these solutions may probably be of limited success if fundamental issues of access to healthcare, as well as improvements in the economic and physical environments in which people live, are not considered. These broader approaches, which include attention to the root-social and economic-causes of health inequalities, are necessary to achieve public health's dual objectives of improving health for all and narrowing inequalities.

\section{Authors' affiliations}

A M Karpati, M T Bassett, C McCord, New York City Department of Health and Mental Hygiene, New York, USA

Competing interests: None.

Ethical approval: This study did not involve human subjects, and therefore did not require institutional review.

\section{REFERENCES}

1 Boston Public Health Commission. Disparities project data report. http:// www.bphc.org/director/disp_data.asp (accessed 21 Sept 2006).

2 Robbins JM, Webb DA. Neighborhood poverty, mortality rates, and excess deaths among African Americans: Philadelphia 1999-2001. J Health Care Poor Underserved 2004; 15:530-7.

3 The Los Angeles County Department of Health Services and The UCLA Center for Health Policy Research. The burden of disease in Los Angeles county, 2000. http://lapublichealth.org/epi/reports/dburden.pdf (accessed 21 Sept 2006).

4 Krieger N, Chen JT, Waterman PD, et al. Race/ethnicity, gender, and monitoring socioeconomic gradients in health: a comparison of area-based socioeconomic measures--the public health disparities geocoding project. Am J Public Health 2003;93:1655-71.

5 Shaw M, Davey SG, Dorling D. Health inequalities and new labour: how the promises compare with real progress. BMJ 2005;330:1016-21.

6 Statistics Canada. Trends in mortality by neighborhood income in urban Canada from 1971 to 1996, Statistics Canada, Catalogue 82-003, Supplement to Health Reports. Vol 13. Statistics Canada, 2002.

7 Fukuda Y, Nakamura K, Takano T. Municipal socioeconomic status and mortality in Japan: sex and age differences, and trends in 1973-1998. Soc Sci Med 2004;59:2435-45.

8 Office of Vital Statistics. New York City Department of Health and Mental Hygiene. Summary of vital statistics 2002 The City of New York. New York, NY: NYC DOHMH, 2002

9 Anderson RN, Miniño AM, Hoyert DL, et al. Comparability of cause of death between ICD-9 and ICD-10: preliminary estimates. National vital statistics reports, Vol 49, number 2. Hyattsville, MD: National Center for Health Statistics, 2001

10 Fisher GM. The development and history of the poverty thresholds. Soc Security Bull. 1992;55: 3-14, http://www.census.gov/hhes/www/poverty/ povdef.html\#3 (accessed 21 Sept 2006).

11 Krieger N, Chen JT, Waterman PD, et al. Geoding and monitoring of US socioeconomic inequalities in mortality and cancer incidence: does the choice of area-based measure and geographic level matter? Am J Epidemiol 2002;156:471-82.

12 New York City. Department of City Planning website. http://www.nyc.gov/ $\mathrm{html} / \mathrm{dcp} / \mathrm{html} /$ census/popdiv.shtml (accessed 21 Sept 2006).

13 Elliott $P$, Wartenberg D. Spatial epidemiology: current approaches and future challenges. Environ Health Perspect 2004; 112:998-1006.

14 Harvard School of Public Health. The Public Health disparities geocoding project monograph. http://www.hsph.harvard.edu/thegeocodingproject/ webpage/monograph/publications.htm (accessed 21 Sept 2006).

15 Rothman KJ, Greenland S. Modern epidemiology, 2nd edn. Philadelphia: Lippincott-Raven, 1998.

16 Mackenbach JP, Kunst AE. Measuring the magnitude of socioeconomic inequalities in health: an overview of available measures illustrated with two examples from Europe. Soc Sci Med 1997;44:757-71.

17 Wagstaff A, Paci P, van Doorslaer E. On the measurement of inequalities in health. Soc Sci Med 1991;33:545-57.

18 Fordyce EJ, Singh TP, Nash D, et al. Survival rates in NYC in the era of combination ART. J Acquir Immune Defic Syndr 2002;30:111-18.

19 Thorpe LE, MacKenzie K, Perl S, et al. NYC Vital signs: one in 6 New York City adults is obese. New York: New York City Department of Health and Mental Hygiene, 2003, http://www.nyc.gov/html/doh/downloads/pdf/ survey/survey-2003obesity.pdf.

20 Thorpe LE, Mostashari F, Berger DK, et al. NYC vital signs: diabetes is epidemic. New York: New York City Department of Health and Mental Hygiene, 2003, http://www.nyc.gov/html/doh/downloads/pdf/survey/ survey-2003obesity.pdf.

21 Diez Roux AV. A glossary for multilevel analysis. J Epidemiol Community Health 2002;56:588-94.

22 Census of population and housing, 1990. Public Law (P.L.) 94-171. Washington: US Census Bureau, 1991.

23 New York City Department of City Planning. http://www.nyc.gov/html/ $\mathrm{dcp} / \mathrm{html} /$ census/adjustment_issues.html (accessed 21 Sept 2006)

24 Fang J, Bosworth W, Madhavan S, et al. Differential mortality in New York city (1988-1992). Part two: excess mortality in the south Bronx. Bull N Y Acad Med 1995;72:483-99.

25 Fang J, Madhavan S, Bosworth W, et al. Residential segregation and mortality in New York City. Soc Sci Med 1998:47:469-76.

26 McCord C, Freeman HP. Excess mortality in Harlem. N Engl J Med 1990;322:173-7. 